Article

\title{
On the Effect of Nanoparticle Surface Chemistry on the Electrical Characteristics of Epoxy-Based Nanocomposites
}

\author{
Celia Yeung ${ }^{\dagger}$ and Alun S. Vaughan ${ }^{*}+$ \\ Department of Electronics and Computer Science, University of Southampton, Southampton SO17 1BJ, UK; \\ miss.c.yeung@googlemail.com \\ * Correspondence: asv@ecs.soton.ac.uk; Tel.: +44-(0)23-8059-3398 \\ + These authors contributed equally to this work.
}

Academic Editor: Frank Wiesbrock

Received: 26 January 2016; Accepted: 16 March 2016; Published: 6 April 2016

\begin{abstract}
The effect of nanosilica surface chemistry on the electrical behavior of epoxy-based nanocomposites is described. The nanosilica was reacted with different volumes of (3-glycidyloxypropyl)trimethoxysilane and the efficacy of the process was demonstrated by infrared spectroscopy and combustion analysis. Nanocomposites containing $2 \mathrm{wt} \%$ of nanosilica were prepared and characterized by scanning electron microscopy (SEM), AC ramp electrical breakdown testing, differential scanning calorimetry (DSC) and dielectric spectroscopy. SEM examination indicated that, although the nanoparticle dispersion improved somewhat as the degree of surface functionalization increased, all samples nevertheless contained agglomerates. Despite the non-ideal nature of the samples, major improvements in breakdown strength (from $182 \pm 5 \mathrm{kV} \cdot \mathrm{mm}^{-1}$ to $268 \pm 12 \mathrm{kV} \cdot \mathrm{mm}^{-1}$ ) were observed in systems formulated from optimally treated nanosilicas. DSC studies of the glass transition revealed no evidence for any modified interphase regions between the nanosilica and the matrix, but interfacial effects were evident in the dielectric spectra. In particular, changes in the magnitude of the real part of the permittivity and variations in the interfacial $\alpha^{\prime}$-relaxation suggest that the observed changes in breakdown performance stem from variations in the polar character of the nanosilica surface, which may affect the local density of trapping states and, thereby, charge transport dynamics.
\end{abstract}

Keywords: nanoparticle; surface functionalization; nanocomposite; morphology; dielectric breakdown strength; dielectric relaxation

\section{Introduction}

Composites have long been used in a wide range of different applications since, by combining two or more components, it is possible to generate material systems with improved properties. Nevertheless, the need for new materials with increased functionality has led to increasing interest in a new generation of composite materials, namely nanocomposites, since these have the potential to deliver combinations of properties that are not accessible through other routes [1,2]. These filled systems differ from conventional composite materials as the filling phase measures a maximum of $100 \mathrm{~nm}$ in at least one dimension and, consequently, the specific interfacial area between the matrix and the filler is large. Indeed, it has been suggested that many aspects of nanocomposite behavior are dominated by interfacial effects related to the presence of interphases, which constitute a significant volume fraction of the system [3].

Although considerable initial effort was focused on generating nanocomposites with tailored thermomechanical properties, the concept of "nanodielectrics" was introduced by Lewis in 1994 [3] 
and quickly gathered momentum in the field of electrical insulation. As the demands on electrical power equipment grow, so do those imposed on their insulation, and may include: improved electrical breakdown strength, reduced dielectric loss, increased thermal conductivity, modified charge transport dynamics, etc. In the case of nanodielectrics, many beneficial effects have been attributed to the introduction of nanoparticles [4-6], but, as a consequence of their nanometric size, nanofillers tend to aggregate prior to and during nanocomposite production, which can impair properties. In particular, the use of polar fillers in non-polar dielectric media can be problematical, as typical mixing techniques are in constant competition with high surface energies and electrostatic forces that can adversely affect the homogeneity of the nanofiller dispersion within the matrix.

To address such compatibility issues, many studies have employed the use of coupling agents, where organofunctional surface reactants are used to modify the mineral substrate surface in order to improve interactions between the nanofiller and the matrix polymer. One of the most commonly employed coupling strategies exploits organosilanes and a number of publications have shown how the use of such compounds can lead to improved filler dispersion in nanodielectrics, thereby enhancing the resulting electrical properties of the system $[7,8]$. Determining the optimum quantity of coupling agent for functionalization is, however, of great importance. If insufficient coupling agent is used, the interactions at the nanofiller-matrix interface will not be optimal and weaker matrix bonding may result while, if excess coupling agent is used, self-condensation may prove disadvantageous [7]. Methods for estimating the optimum quantity of coupling agent have therefore been proposed in a number of studies. Some authors have attempted to calculate the required quantity of coupling agent based on the number of active sites on the surface of the nanofiller that is available for chemical bonding [9], while others have used the size of the nanoparticles and the thickness of a monolayer of coupling agent [7] to evaluate the required volume of reagent. Another approach has involved calculations based on the surface area of the filling phase and the specific wetting surface of the silane coupling agent [10]. Despite this, there have been few detailed studies in which the degree of functionalization has been treated as a variable parameter in studies of nanocomposite systems [11,12].

This study set out with the objective of systematically varying the functionalization conditions of nanosilica $\left(\mathrm{SiO}_{2}\right)$, with the aim of determining its effect on the structure and dielectric properties of a series of epoxy-based nanodielectrics. Specifically, the intention of the work was to test the generally accepted notion that, in nanodielectrics, surface interactions determine nanoparticle dispersion and that nanoparticle dispersion determines macroscopic properties through the formation of consequent interphases. Two functionalization methodologies have been considered, which involved hydrous and anhydrous conditions; only the former is reported here.

\section{Materials and Methods}

\subsection{Materials}

The epoxy resin used in this study was a diglycidyl ether of bisphenol A with an epoxide equivalent molar mass of $172-176 \mathrm{~g} \cdot \mathrm{mol}^{-1}$; D.E.R. ${ }^{\mathrm{TM}} 332$, obtained from Sigma Aldrich, St. Louis, MO, USA. This was cured using a polyetheramine curing agent with an amine hydrogen equivalent molar mass of $60 \mathrm{~g} \cdot \mathrm{mol}^{-1}$; Jeffamine D-230, obtained from Huntsman Corporation, The Woodlands, TX, USA. The nanosilica was purchased from Sigma Aldrich and is characterized by a quote filler size of 10-20 nm; this was pre-treated with (3-glycidyloxypropyl)trimethoxysilane (GLYMO-Z-6040 from Dow Corning, Auburn, MI, USA) using the procedure described below.

Samples of nanosilica were modified to varying degrees by treating the nanoparticles with different quantities of coupling agent. Simplistic calculations suggest that, to functionalize $100 \mathrm{mg}$ of spherical nanosilica particles $10-20 \mathrm{~nm}$ in diameter with a monolayer of GLYMO, $20 \mathrm{mg}$ of the coupling agent would be required; that is, a ratio of 5 parts nanosilica to 1 part GLYMO by mass. However, due to the uncertainties inherent in this calculation, seven samples were prepared using various ratios of nanosilica to GLYMO that span the above estimate (see Table 1). For this, 
the appropriate quantity of coupling agent was added to a pre-sonicated suspension composed of $800 \mathrm{mg}$ of nanosilica in $25 \mathrm{~mL}$ of methanol and shaken vigorously. To inhibit GLYMO self-condensation reactions, the above reaction was conducted under acidic conditions; acetic acid was added according to the procedure specified by Ash et al. [13]. After $46 \mathrm{~h}$, the nanosilica was recovered by first centrifuging and then washing with fresh methanol; this procedure was repeated five times to ensure that all excess coupling agent and all acid residues were removed from the system. Finally, the nanosilica was dried thoroughly at $40^{\circ} \mathrm{C}$ under vacuum, to remove any residual solvent.

Table 1. Degree of nanosilica functionalization and designated codes for each sample. All nanocomposites contain $2 \mathrm{wt} \%$ of the appropriate nanosilica.

\begin{tabular}{ccc}
\hline Nanocomposite & Nanosilica Filler & Ratio of Nanosilica to GLYMO \\
\hline EPX & - & - \\
NCU & NSU & $1: 0$ \\
NC0 & NS0 & $1: 0$ \\
NC1 & NS1 & $8: 1$ \\
NC2 & NS2 & $4: 1$ \\
NC4 & NS4 & $2: 1$ \\
NC8 & NS8 & $1: 1$ \\
NC16 & NS16 & $1: 2$ \\
NC20 & NS20 & $2: 5$ \\
\hline
\end{tabular}

\subsection{Nanocomposite Preparation}

Nanocomposite samples were prepared from the above starting materials using the following procedure. First, $150 \mathrm{mg}$ of the required nanosilica was introduced, with stirring, to $5.58 \mathrm{~g}$ of the D.E.R. ${ }^{\text {TM }} 332$ and sonicated for $1 \mathrm{~h}$ using a UP200s probe sonicator, Hielscher Ultrasonics, Teltow, Germany ( $110 \mathrm{~W} ; 55 \%$ amplitude; pulsed mode with $0.7 \mathrm{~s}$ on, $0.3 \mathrm{~s}$ off). In order to prevent any excessive increase in temperature, the specimen was placed in a water bath throughout the sonication process and the water was replaced every $15 \mathrm{~min}$. After sonication was complete, $1.92 \mathrm{~g}$ of hardener was added, as required to produce the optimum stoichiometric ratio of 1000:344 (epoxy:hardener), and the resulting mixture was thoroughly stirred with a magnetic stirrer for $15 \mathrm{~min}$ before being degassed under dynamic vacuum for $15 \mathrm{~min}$. The resulting resin was then poured into a steel mold (pre-heated to $50^{\circ} \mathrm{C}$ ) containing a spacer, nominally $70 \mu \mathrm{m}$ in thickness; all mold components were lightly coated with QZ-13 release agent, Huntsman Corporation, to aid removal of the resulting film specimen. All samples were cured at $100{ }^{\circ} \mathrm{C}$ for $4 \mathrm{~h}$ before, finally, being dried under vacuum at $40^{\circ} \mathrm{C}$ for two weeks prior to testing.

\subsection{Material Characterisation}

To evaluate the effect of the surface functionalization treatment described above, specimens of the as-supplied nanosilica (i.e., nanosilica NSU), NS0, NS4 and NS20 were subjected to combustion/CHN analysis (MEDAC Ltd., Woking, UK.), which, in this context, provides an indicative measure of the carbon content of each material. In addition, FTIR spectra were obtained from all nanosilicas, using a Thermo Nicolet 380 FTIR spectrometer (Thermo Scientific, Waltham, MA, USA) fitted with a Golden Gate single reflection diamond attenuated total reflectance (ATR) attachment. Spectra were collected with the spectrometer set in reflectance mode for wavenumbers ranging from $4000 \mathrm{~cm}^{-1}$ to $400 \mathrm{~cm}^{-1}$, using 32 scans at a resolution of $4 \mathrm{~cm}^{-1}$. All spectra were finally normalized with respect to the peak at $1100 \mathrm{~cm}^{-1}$, which, being related to the silica phase, provides a convenient reference.

The dispersion state of the nanofiller within each nanocomposite was examined using a field emission gun scanning electron microscope (FEG-SEM) 6500F SEM (JEOL Ltd., Tokyo, Japan). For this, film samples prepared as above were immersed in liquid nitrogen before being fractured to expose 
an internal surface. Images were obtained from gold sputter-coated specimens using an accelerating voltage of $15 \mathrm{kV}$ and a working distance of $10 \mathrm{~mm}$.

\subsection{Nanocomposite Properties}

AC electrical breakdown tests were conducted at room temperature on nominally $70 \mu \mathrm{m}$ thick film specimens, in line with the ASTM D149 standard. Twenty random sites on each nanocomposite film were sequentially positioned between two $6.3 \mathrm{~mm}$ spherical ball bearing electrodes, whilst immersed in silicone oil and subjected to a $50 \mathrm{~Hz}$ AC ramp voltage that was increased at a rate of $50 \mathrm{~V} \cdot \mathrm{s}^{-1}$ (RMS) until failure. The ball bearing electrodes were routinely replaced after eight tests, to eliminate the possibility of surface pitting affecting the derived data. The sample thickness at each breakdown site was subsequently measured, such that the associated field at breakdown could be determined from the breakdown voltage. The resulting AC breakdown field data were processed using Weibull 7++ software (Reliasoft Corporation, Tucson, AZ, USA), assuming a two parameter Weibull distribution. The Weibull scale parameter, $\alpha$, and shape parameter, $\beta$, were determined for each data set, together with $90 \%$ maximum likelihood confidence bounds.

The glass transition of each specimen was evaluated using a Perkin Elmer, Waltham, MA, USA, DSC 7 differential scanning calorimeter (DSC), after calibration with high purity indium. Samples weighing $5.0 \pm 0.5 \mathrm{mg}$ were enclosed in aluminum cans and held at $50{ }^{\circ} \mathrm{C}$ for $1 \mathrm{~min}$, before the specimen temperature was raised from 50 to $120^{\circ} \mathrm{C}$ at a rate of $10^{\circ} \mathrm{C} \cdot \mathrm{min}^{-1}$ and then reduced rapidly to a nominal $30^{\circ} \mathrm{C}$. This procedure was executed twice in succession to erase the thermal history of the sample. Data for baseline correction were acquired from an unfilled DSC can and subtracted from the sample material second scan. The resulting baseline corrected data were finally normalized with respect to sample mass and the glass transition temperature, $T_{\mathrm{g}}$, of each nanocomposite was determined by taking the mid-point of the step-change in the DSC heat flow data. The associated change in specific heat capacity, $\Delta C_{p}$, and the width of the glass transition, $\Delta T_{\mathrm{g}}$, were also routinely evaluated.

The dielectric response of the various epoxy systems was recorded using a Schlumberger, Houston, TX, USA, SI 1260 impedance/phase gain analyzer, in conjunction with a Solatron, Farnborough, UK, 1296 dielectric interface and a purpose built test cell with heating capability. Samples were prepared by sputter coating opposing circular gold electrodes measuring $32 \mathrm{~mm}$ in diameter onto each surface of the epoxy film. Dielectric spectra were obtained from each sample upon the application of a sinusoidal AC voltage of amplitude $1 \mathrm{~V}$. Data were obtained at $20^{\circ} \mathrm{C}$ intervals from 20 to $100{ }^{\circ} \mathrm{C}$, over the frequency range $0.1 \mathrm{~Hz}$ to $0.1 \mathrm{MHz}$.

\section{Results}

\subsection{Nanosilica Functionalization}

The objective of surface treatment with an organosilane is to provide an amphiphilic bridge to promote desirable interactions between the filler and the surrounding matrix. The formulation used to produce each of the nanosilicas is listed in Table 1; each nanocomposite contained $2 \mathrm{wt} \%$ of the indicated nanosilica. The hydrolysis of the methoxy functional groups on the organosilane results in the formation of organosilane moieties with reactive silanol groups that can: (a) undergo self-condensation; or (b) react with hydroxyl groups on the surface of the nanosilica. Hydrogen bonds formed at the filler surface are replaced by covalent bonds upon drying, resulting in the functionalization of the nanofiller $[7,14]$. Figure 1 compares the weight percentages of carbon in untreated and treated samples of nanosilica. These data indicate that the carbon content in NSU and NS0 is equivalent; neither has been processed with GLYMO. This result also indicates that exposure to the acidic methanolic solvent does not lead to the adsorption of appreciable organic residues. The increasing levels of carbon detected in NS4 and NS20, although within the measurement uncertainties, are suggestive of successful surface modification. 


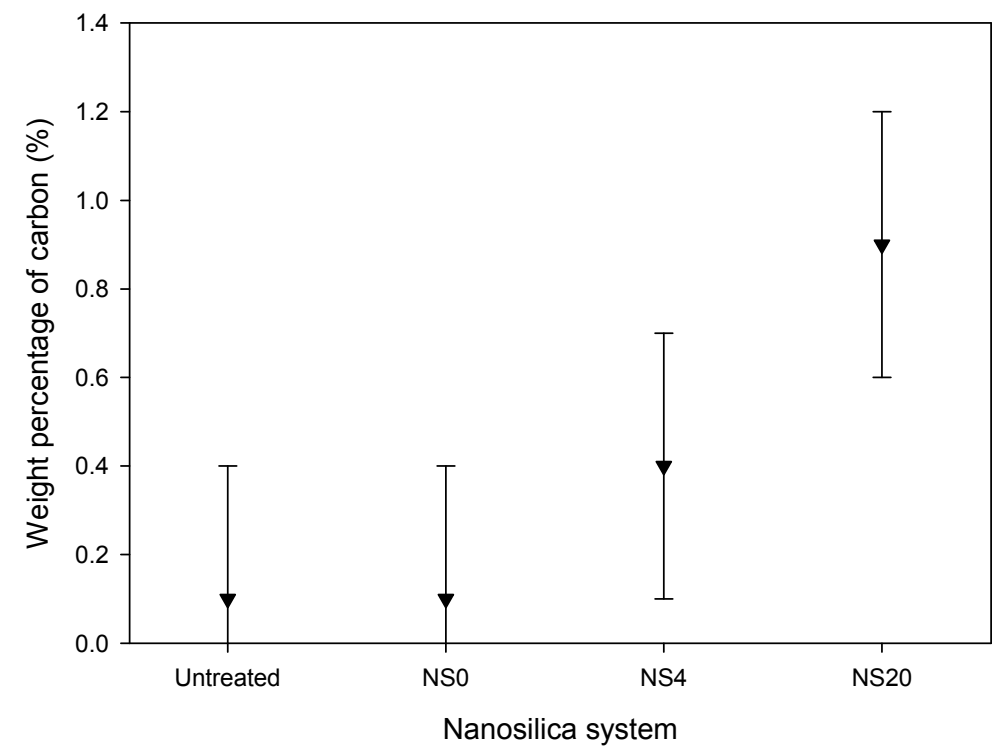

Figure 1. Combustion analysis data indicating an increase in nanosilica carbon content with increasing degree of surface modification. The error bars correspond to the accuracy of $\pm 0.30 \%$ absolute quoted by MEDAC Ltd., Woking, UK.

Figure 2 contains Fourier transform infrared (FTIR) spectra obtained from all the nanocomposite systems listed in Table 1. All spectra show absorption bands from 1200 to $1000 \mathrm{~cm}^{-1}$, at $805 \mathrm{~cm}^{-1}$ and at $471 \mathrm{~cm}^{-1}$, which are characteristic of asymmetric $\mathrm{Si}-\mathrm{O}-\mathrm{Si}$ stretching, deformation of $\mathrm{SiO}_{4}$ tetrahedra and $\mathrm{O}-\mathrm{Si}-\mathrm{O}$ deformation respectively [15]. Data acquired from the GLYMO contain a strong absorption peak at $1250 \mathrm{~cm}^{-1}$, which is a consequence of the presence of the terminal epoxide ring, while the absorption in the range 2850 to $3000 \mathrm{~cm}^{-1}$ is representative of the $\mathrm{CH}_{2}$ groups that are associated with the GLYMO organic backbone [12,16]. Despite the lack of clear epoxide features in the spectra obtained from the surface-modified nanosilicas, there are observable differences in the region 3000 to $3700 \mathrm{~cm}^{-1}$, which is primarily associated with hydroxyl groups. As NSU and NS0 have not been chemically modified, they can be considered chemically equivalent as far as the GLYMO is concerned. Nevertheless, the strength of the hydroxyl band is rather less in the NS0 specimen; a decrease in the hydroxyl band is observed in processed silicas and is attributable to the removal of moisture from the surface during vacuum drying. There is also evidence of a minor additional peak at $2944 \mathrm{~cm}^{-1}$ for all the samples that had been functionalized with the GLYMO, as highlighted in Figure $2 b$, which increases in intensity with the volume of GLYMO used in processing. This feature correlates with the GLYMO CH 2 absorption band indicated by the dotted lines in Figure 2 and therefore provides further evidence in support of the successful functionalization of the nanosilica.

Published accounts of organosilane chemistry describe the chemical pathways in terms of hydrolysis and condensation [14,17], before hydrogen bonds are formed with the surface of the substrate. However, such an idealized outcome constitutes an unlikely extreme, with other conformations being possible. In such cases, unreacted hydroxyl (silanol) groups will be retained within a disordered organosilica surface layer and, consequently, even in the case of NS20, where it would seem that a vast excess of GLYMO has been used, residual hydroxyl groups still exist near the particle surface, as evinced by Figure 2. 


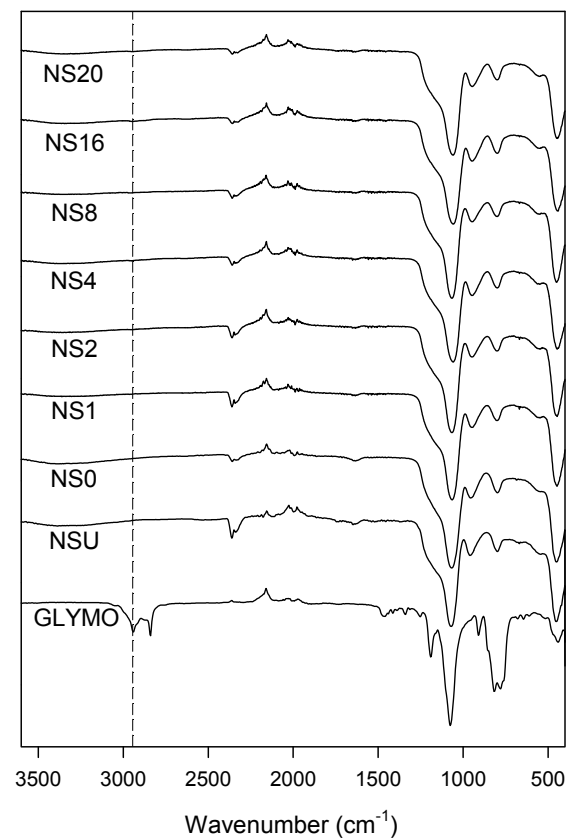

(a)

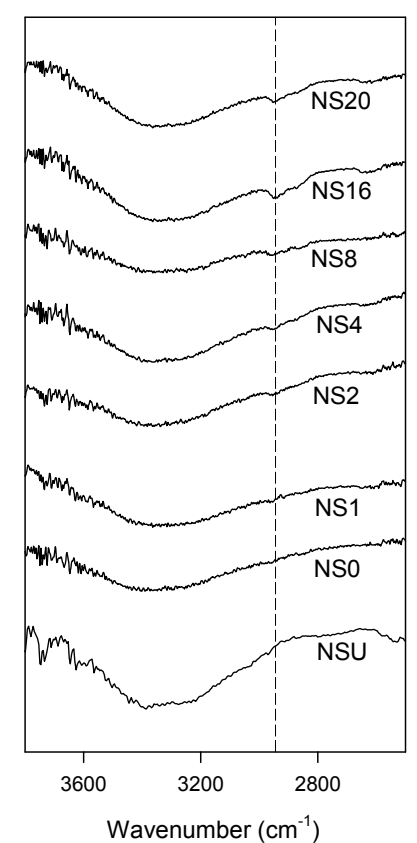

(b)

Figure 2. FTIR spectra obtained from all the nanosilica systems used in this study; the vertical dashed line indicates $2944 \mathrm{~cm}^{-1}$. (a) full spectral range; (b) detail showing the hydroxyl region.

\subsection{Nanocomposite Morphology}

Although it is generally accepted that appropriate functionalization of nanoparticles leads to enhanced dispersion, we are not aware of any previous attempts to investigate how varying the degree of functionalization affects this. Figure 3a contains a typical scanning electron microscope (SEM) image of a cryofracture surface in an unfilled epoxy, which reveals a smooth texture in accordance with its amorphous structure. This image is in line with published work [18]. The surface striations indicated by the arrow are fractography features and lie orthogonal to the local crack propagation direction. In comparison, all nanocomposites were found to be characterized by much rougher surface textures that, locally, provide evidence of significant degrees of agglomeration, as shown in Figure 3b-d. Figure 3b shows an agglomerated region in sample NC0 that contains, in addition, bow-like fractography features associated with crack pinning [19]. Increasing the quantity of GLYMO used in functionalization results in a less agglomerated structure and in rather finer matrix surface textures.

While the presence of agglomerates in nanocomposites is not uncommon [20], the overall quality of the specimens shown above are markedly inferior to those reported by Nguyen et al. [18] in a recent study of epoxy/silica nanocomposites. In the work of Nguyen et al. [18], the nanosilica was introduced using a proprietary masterbatch system, Nanopox E 470 (supplied by Nanoresins), where the nanosilica is described as consisting of an agglomerate-free colloidal dispersion of surface-modified synthetic $\mathrm{SiO}_{2}$ with an average particle diameter of $20 \mathrm{~nm}$. It is evident from the study of Nguyen et al. [18] that it is possible to produce agglomerate-free materials through the use of systems such as Nanopox E 470, albeit that this comes at the cost of neither knowing the nanofiller surface chemistry nor being able to modify it as required. 


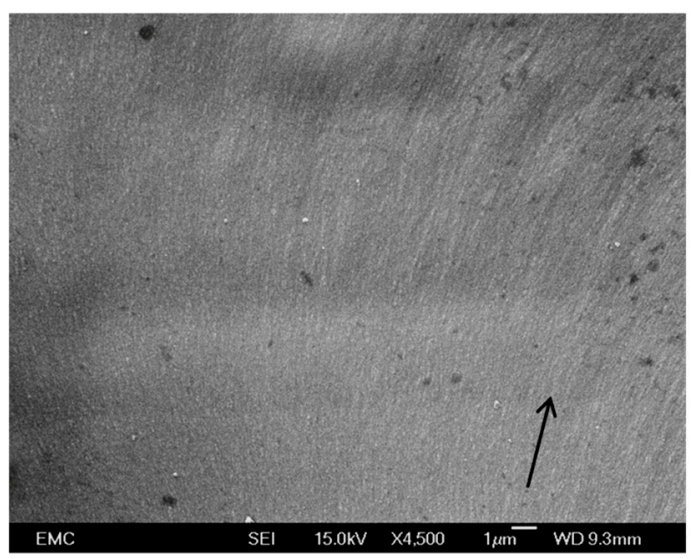

(a)

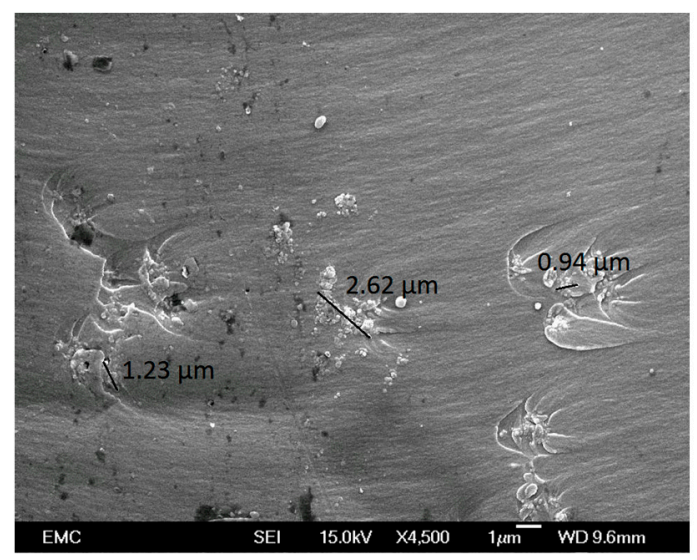

(c)

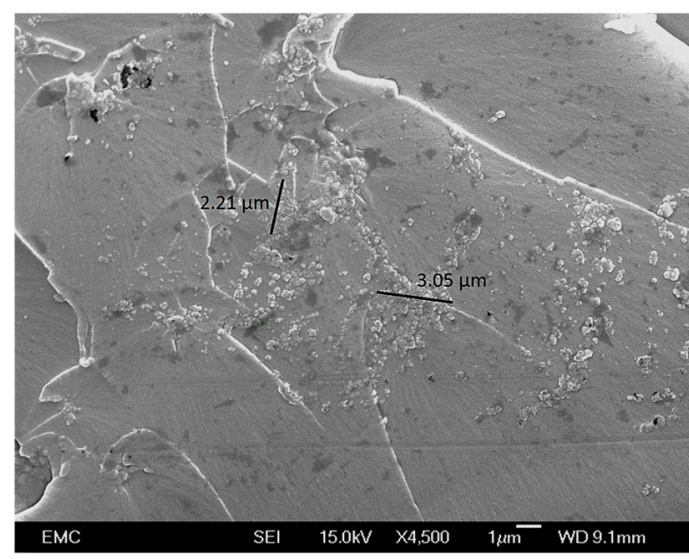

(b)

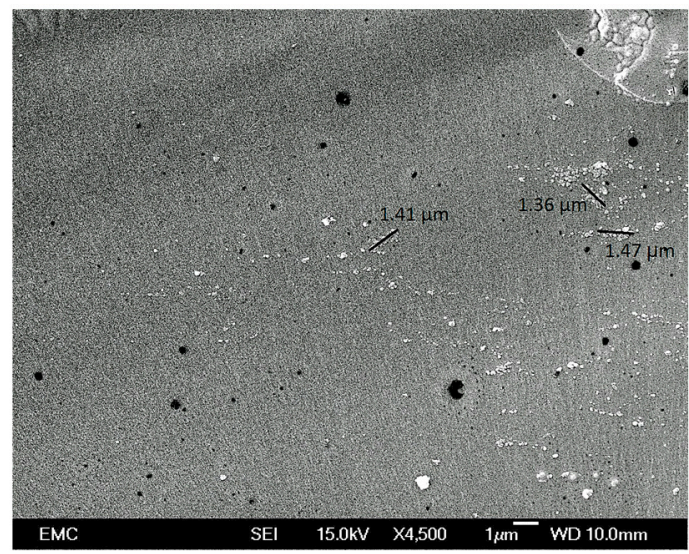

(d)

Figure 3. SEM micrographs showing representative fracture surfaces through a range of the materials considered here: (a) the unfilled epoxy specimen (EPX); (b) NC0; (c) NC4; and (d) NC16.

\subsection{Dielectric Breakdown Strength}

Table 2 contains breakdown parameters obtained from all the samples considered here, assuming two parameter Weibull statistics. From this, the breakdown strength, $E_{\mathrm{b}}$, of the unfilled resin, which in line with convention we equate to the Weibull $\alpha$ parameter, is given by $182 \pm 5 \mathrm{kV} \cdot \mathrm{mm}^{-1}$. This constitutes a reference point for all the other systems. Adding nanosilica directly without surface modification or solvent processing results in a decrease in breakdown strength to $173 \pm 6 \mathrm{kV} \cdot \mathrm{mm}^{-1}$. Reductions in breakdown strength on the inclusion of a nanofiller have been seen in many studies and have been ascribed to a number of effects, notably nanoparticle agglomeration [21,22]. Alternatively, a reduction in breakdown strength may stem from the existence of adsorbed moisture on the filler used to formulate this system (i.e., NSU), as deduced from the infrared data. The presence of hydroxyl groups on unfunctionalized nanosilica will promote adsorption of water molecules, which has previously been linked to reduced breakdown strength [23,24] and described by Zou's water model [25]. Indeed, the breakdown strength of the system containing the NC0 nanosilica, which has been subjected to both sonication and thorough drying, is increased by some $50 \mathrm{kV} \cdot \mathrm{mm}^{-1}$ compared with NSU, where neither process was used. Increasing the mass of GLYMO used in the functionalization process results in a further increase in breakdown strength; the highest $\alpha$ value of $268 \pm 12 \mathrm{kV} \cdot \mathrm{mm}^{-1}$ being obtained from the system containing $2 \mathrm{wt} \%$ of NC8. 
Table 2. Weibull parameters that characterize the breakdown behavior of the unfilled and filled epoxy systems.

\begin{tabular}{|c|c|c|}
\hline Sample & $E_{\mathrm{b}}\left(\mathrm{kV} \cdot \mathrm{mm}^{-1}\right)$ & $\beta$ \\
\hline EPX & $182 \pm 5$ & $14 \pm 4$ \\
\hline NCU & $173 \pm 6$ & $13 \pm 5$ \\
\hline NC0 & $238 \pm 10$ & $9 \pm 3$ \\
\hline $\mathrm{NC1}$ & $242 \pm 7$ & $13 \pm 4$ \\
\hline NC2 & $257 \pm 19$ & $5 \pm 1$ \\
\hline NC4 & $258 \pm 11$ & $9 \pm 2$ \\
\hline NC8 & $268 \pm 12$ & $8 \pm 2$ \\
\hline NC16 & $265 \pm 16$ & $6 \pm 2$ \\
\hline NC20 & $244 \pm 13$ & $7 \pm 4$ \\
\hline
\end{tabular}

In view of the effect on breakdown strength of varying the chemical treatment and, by implication, nanoparticle/matrix interactions and resulting interphase regions [26-29], the effect of varying the nanoparticle surface chemistry on molecular dynamics [27-29] was examined thermally (i.e., through DSC) and electrically (i.e., through dielectric spectroscopy).

\subsection{The Glass Transition}

All of the samples considered in this study exhibit a classical DSC glass transition, namely a singular step-change in heat capacity. The width of the transition, $\Delta T_{\mathrm{g}}$, did not vary systematically with material formulation and always fell in the range $13.3 \pm 1.5^{\circ} \mathrm{C}$; comparable results have been reported elsewhere [18]. Figure 4a shows the effect on $T_{\mathrm{g}}$ of varying the surface chemistry of the nanosilica. From this it is evident that introducing the unfunctionalized nanofiller (NC0) results in a small increase in $T_{\mathrm{g}}\left(0.8^{\circ} \mathrm{C}\right)$, compared with the unfilled epoxy (EPX). Although this variation is less than the uncertainty in these data, a similar increase was reported by Couderc et al. [30], who observed a $0.5{ }^{\circ} \mathrm{C}$ increase in $T_{\mathrm{g}}$ for the same epoxy system on adding $2.5 \mathrm{wt} \%$ of nanosilica. For samples containing functionalized nanosilicas, the mean value of $T_{\mathrm{g}}$ initially decreases before increasing slightly again. Comparing EPX $\left(T_{\mathrm{g}}=80.7 \pm 2{ }^{\circ} \mathrm{C}\right)$ with $\mathrm{NC} 4\left(T_{\mathrm{g}}=74.2 \pm 2{ }^{\circ} \mathrm{C}\right)$, for example, the difference in $T_{\mathrm{g}}$ between these two systems exceeds the uncertainties in the measurements and therefore, although the error bars overlap when considering any adjacent pair of points in Figure 4a, we suggest that the general trend indicated by the dashed line is real. To test this assertion, the change in the heat capacity, $\Delta C_{p}$, across the glass transition was determined for all samples and the effect of surface functionalization on this quantity is shown in Figure $4 \mathrm{~b}$. Where $T_{\mathrm{g}}$ is high in Figure $4 \mathrm{a}$, generally, $\Delta C_{\mathrm{p}}$ is low in Figure $4 \mathrm{~b}$; this anti-correlation is consistent with effects seen elsewhere in comparable systems [18], suggesting that the associated variations in $T_{\mathrm{g}}$ are indeed significant. Significant variations in the parameter $\Delta C_{p}$ have been seen in polyurethane-based nanocomposites containing organically modified montmorillonite (MMT), where a monotonic reduction in $\Delta C_{p}$ was seen as the volume of MMT in the system increased (0-5.7 vol \%) [31]. This was interpreted in terms of an increasing rigid amorphous fraction, where reduced segmental mobility occurs as a consequence of immobilization within MMT tactoids. A comparable analysis is not possible here, since Figure $4 \mathrm{~b}$ shows that $\Delta C_{\mathrm{p}}$ both increased and decreased relative to the case of the unfilled system. Previously, it has been suggested that suitably modifying the surface chemistry of nanoparticles will restrict the overall mobility of the polymer chains within a nanocomposite, thereby increasing $T_{\mathrm{g}}$ [32-34]; in the case of nanocomposites containing graphitic nanofillers, the observed marked increase in $T_{\mathrm{g}}$ has been associated with a catalytic action of the nanofiller on the epoxy crosslinking reaction [35]. Elsewhere, it has been claimed that a reduction in $T_{\mathrm{g}}$ may be a consequence of poor interactions between the two phases [36]. However, the effects seen in Figure 4 are difficult to rationalize in either way. In the case of anhydride cured resins it has been demonstrated [18] that a change in the stoichiometric ratio of epoxy: anhydride results in a systematic variation in $T_{\mathrm{g}}$ and, since the various nanosilica systems discussed 
above may be expected to differ with respect to the number of epoxide groups adjacent to the surface, it is pertinent to consider the extent to which this may influence the overall stoichiometry of the cure reaction. Even taking the extreme case of NS20 and, unreasonably, assuming that all of the added GLYMO became bonded to the nanoparticles, this would only equate to an increase in epoxide content of $\sim 3 \mathrm{~mol} \%$. The variations in $T_{\mathrm{g}}$ seen above cannot therefore be explained by gross stoichiometry effects and the invariance in the width of the glass transition indicates that no extensive interphase regions exist where local interactions affect main-chain dynamics.

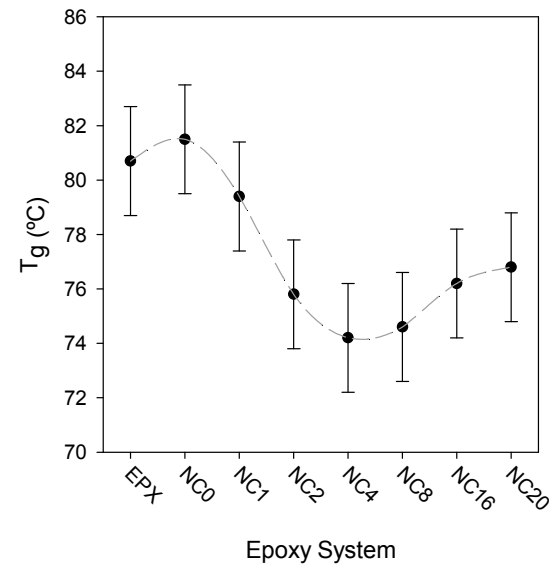

(a)

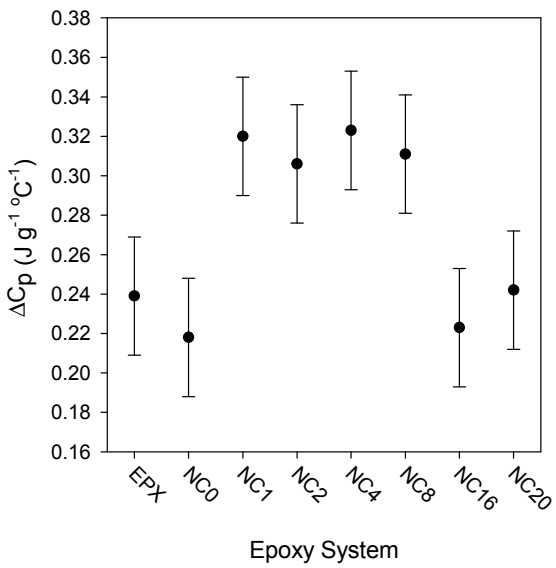

(b)

Figure 4. Effect of nanosilica surface chemistry on the observed DSC glass transition: (a) variation in the glass transition temperature with material system; and (b) variation in the change in the heat capacity, $\Delta C_{\mathrm{p}}$, across the glass transition with material system.

\subsection{Dielectric Spectroscopy}

Dielectric spectroscopy constitutes a powerful means of probing molecular dynamics in systems such as the nanocomposite samples considered here. Figure 5 presents data obtained from EPX, which reveal features that are typical of an unfilled epoxy $[7,9,30]$. At temperatures below $T_{\mathrm{g}}$, a slight reduction in the real part of the relative permittivity, $\varepsilon_{\mathrm{r}}{ }^{\prime}$, can be seen to occur in the frequency range $10^{4}-10^{5} \mathrm{~Hz}$. This is associated with the $\beta$ relaxation, which has been ascribed to the rotation of the hydroxyether groups $\left[\mathrm{CH}_{2} \mathrm{CH}(\mathrm{OH}) \mathrm{CH}_{2} \mathrm{O}\right]$ in the backbone that results from crosslinking reactions between the epoxy and the hardener [37]. Being associated with segmental mobility, the $\beta$ relaxation has been shown to be related to the mechanical yield behavior of network systems [38]. Data collected from the unfilled EPX at $80^{\circ} \mathrm{C}$ and above are significantly different due to the glass transition which, in the DSC, is observed at $\sim 80^{\circ} \mathrm{C}$. In the data acquired at $100{ }^{\circ} \mathrm{C}$, the $\alpha$ relaxation is clearly visible in both the real and imaginary parts of the relative permittivity in the region 100-1000 Hz. Below this frequency range, the imaginary part of the relative permittivity, $\varepsilon_{\mathrm{r}}{ }^{\prime \prime}$, increases with decreasing frequency and, since $\left(\operatorname{dlog} \varepsilon_{\mathrm{r}}{ }^{\prime \prime}\right) /(\operatorname{dlog} \omega) \approx-1$, we primarily associate this with a conduction process, presumably, as a consequence of the presence of residual chloride ions in the D.E.R. ${ }^{\mathrm{TM}} 332$ epoxy resin [39]. However, in addition, there is an observable increase in the real part of the relative permittivity below $0.2 \mathrm{~Hz}$, which may be associated with some degree of interfacial polarization, as a consequence of the accumulation of charge carriers at the electrodes [40,41].

Figure 6 shows equivalent dielectric data obtained from NC0, from which it is evident that the introduction of $2 \mathrm{wt} \%$ of nanofiller has a marked effect on the dielectric response. At temperatures below the DSC $T_{\mathrm{g}}$, the $\beta$ relaxation is still evident, particularly in the $20^{\circ} \mathrm{C}$ trace but, otherwise, the value of the real permittivity is increased at all frequencies and at all temperatures. This effect is particularly evident below $10 \mathrm{~Hz}$. Although such effects are not uncommon when adding an inorganic filler to a polymer, in the case of a system based upon $2 \mathrm{wt} \%$ of silica (silica real relative permittivity 
$\sim 3.9$ [42]) in an epoxy (epoxy real relative permittivity $\sim 4.0$ from Figure 5a), simple effective medium approaches would not predict such a result. As such, this increase in $\varepsilon_{\mathrm{r}}{ }^{\prime}$ would appear to be a consequence of the presence of nanoparticle/matrix interfaces. At temperatures below $T_{\mathrm{g}},\left(T_{\mathrm{g}}=82{ }^{\circ} \mathrm{C}\right.$ in this system from DSC) the imaginary permittivity data contain a relaxation peak that moves from $\sim 10^{-1} \mathrm{~Hz}$ at $20^{\circ} \mathrm{C}$ to $\sim 10 \mathrm{~Hz}$ at $60^{\circ} \mathrm{C}$; since no equivalent feature can be seen in Figure $5 \mathrm{~b}$, we suggest that this is again a direct consequence of introducing the nanoparticles. Indeed, Couderc et al. [30] have described an $\alpha^{\prime}$ relaxation that they associated with adsorbed water molecules at the interface between the silica and the epoxy, which is also consistent with the increase in the magnitude of $\varepsilon_{\mathrm{r}}{ }^{\prime}$ described above. Although NC0 was thoroughly dried prior to these measurements, this suggests that some residual bound water remains. At temperatures above the DSC $T_{\mathrm{g}}$, the additional internal boundaries between the nanofiller and the matrix lead to a pronounced low frequency polarization effect, which manifests itself as a steep increase in the real part of the relative permittivity below $\sim 1 \mathrm{~Hz}$ at $100{ }^{\circ} \mathrm{C}$. As in the case of the unfilled sample, the imaginary part of the relative permittivity increases markedly once the temperature approaches $T_{\mathrm{g}}$ and, at $100^{\circ} \mathrm{C}$, the low frequency variation of this quantity is close to $\left(\operatorname{dlog} \varepsilon_{\mathrm{r}}{ }^{\prime \prime}\right) /(\mathrm{d} \log \omega)=-1$, indicating that conduction processes within the epoxy matrix are again important.

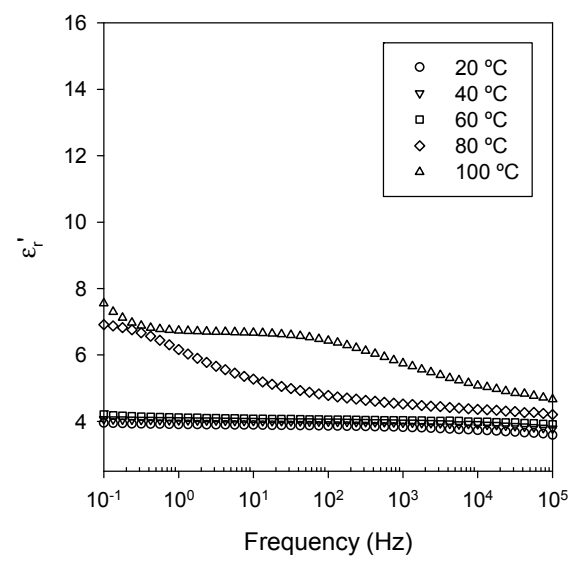

(a)

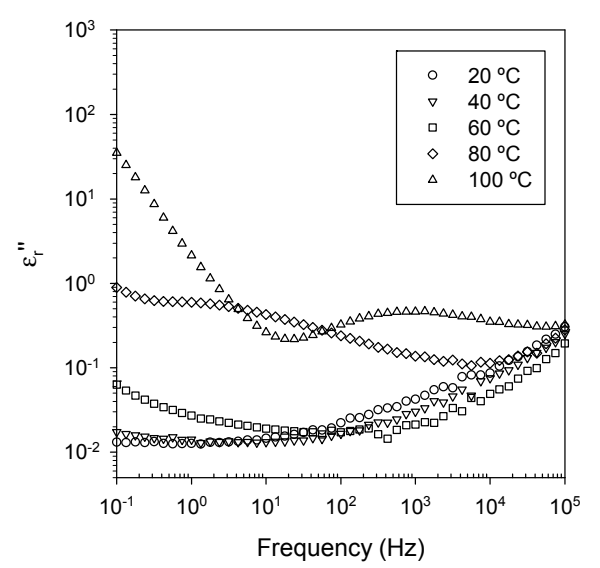

(b)

Figure 5. Dielectric data acquired from the unfilled epoxy (EPX): (a) real part of the relative permittivity; and (b) imaginary part of the relative permittivity.

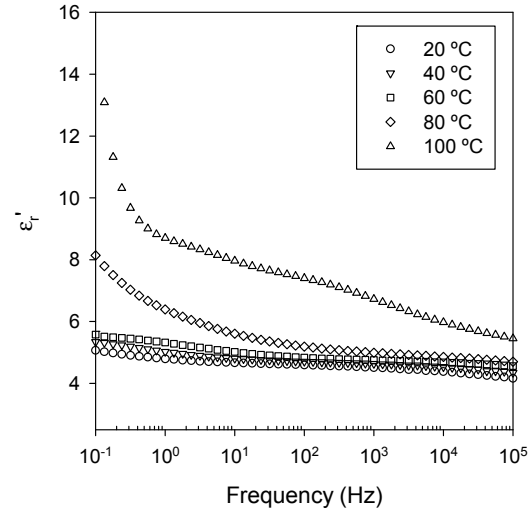

(a)

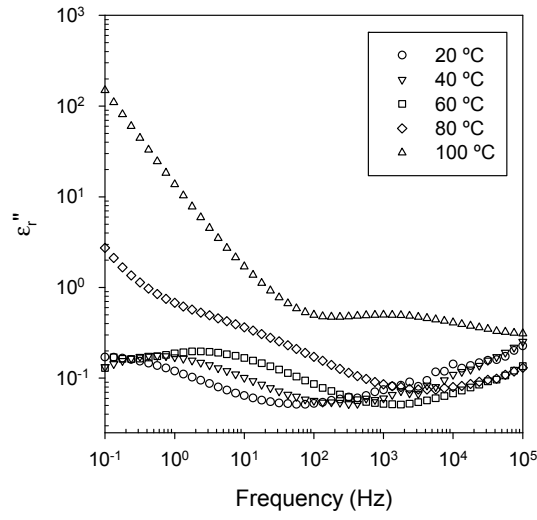

(b)

Figure 6. Dielectric data acquired from NC0, containing untreated nanosilica (NS0): (a) real part of the relative permittivity; and (b) imaginary part of the relative permittivity. 
In summary, the data discussed above can be interpreted in terms of three major processes, in addition to the glass transition:

1. Ionic conduction, which becomes significant in all systems at temperatures above the DSC $T_{\mathrm{g}}$.

2. Nanoparticle/matrix interfacial relaxation effects, that: (a) manifest themselves as an $\alpha^{\prime}$ relaxation peak in the imaginary permittivity; and (b) underlie the overall increase in $\varepsilon_{r}{ }^{\prime}$ seen in the nanocomposite.

3. Maxwell Wagner low frequency interfacial polarization at temperatures above the DSC $T_{\mathrm{g}}$, which appears as a marked increase in the real part of the permittivity at frequencies $<1 \mathrm{~Hz}$ at high temperatures (i.e., $100{ }^{\circ} \mathrm{C}$ in this work).

To demonstrate the effect of surface chemistry on these features, spectra acquired from four different material formulations are compared, for the sake of brevity, at just $60^{\circ} \mathrm{C}$ (i.e., $\sim 20^{\circ} \mathrm{C}$ below the DSC $T_{\mathrm{g}}$ ) and at $100{ }^{\circ} \mathrm{C}$ (i.e., $\sim 20^{\circ} \mathrm{C}$ above the DSC $T_{\mathrm{g}}$ ) in Figures 7 and 8 respectively. From Figure 7 , it is evident that below the DSC $T_{\mathrm{g}}$, surface functionalization has a pronounced effect on both the real and imaginary parts of the relative permittivity. In the case of $\varepsilon_{\mathrm{r}}{ }^{\prime}$ (see Figure 7a), increasing the degree of functionalization progressively reduces this parameter until, in the case of NC16, its value is below that of the unfilled epoxy. The effect of filler loading level on the permittivity of nanocomposites has been considered by many workers and, in some cases, it has been reported that the addition of a low volume fraction of a high permittivity nanofiller can result in a reduction in the real relative permittivity $[43,44]$. While it is commonly proposed that the origin of this effect is related in some way to the existence of nanoparticle/matrix interactions, this assertion has not been fully justified. In this case, a supplementary factor can also be introduced, namely the availability of polar interfacial sites that are available for hydrogen bonding with water. If the overall increase in $\varepsilon_{\mathrm{r}}{ }^{\prime}$ and the $\alpha^{\prime}$ relaxation are indeed associated with adsorbed water molecules at the epoxy/silica interface then, presumably, reacting the hydroxyl groups on $\mathrm{NC} 0$ with increasing quantities of silane will reduce the sites available to bind water, in addition to modifying the local molecular structure. Indeed, from the imaginary relative permittivity data shown in Figure $7 \mathrm{~b}$, it is evident that the $\alpha^{\prime}$ relaxation is much less apparent in all the GLYMO-treated systems, which reinforces this general concept. To conclude, the data shown in Figure 7 demonstrate that the overall dielectric response of a nanocomposite is determined not just by the components and the composition, but also by the nanoparticle surface chemistry and the consequent way in which the components interact. Specifically, the degree of polar character seems to be of considerable importance and not just in terms of matrix compatibility.

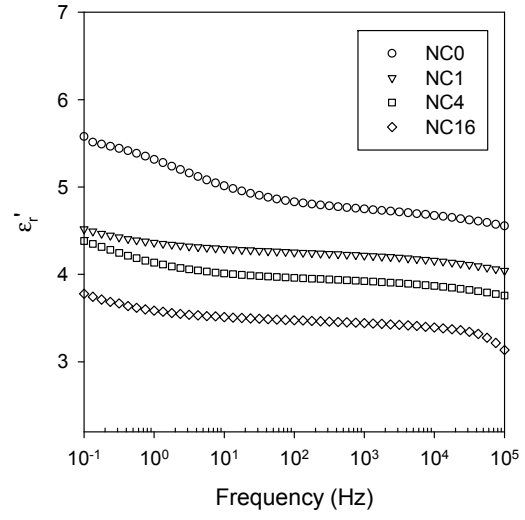

(a)

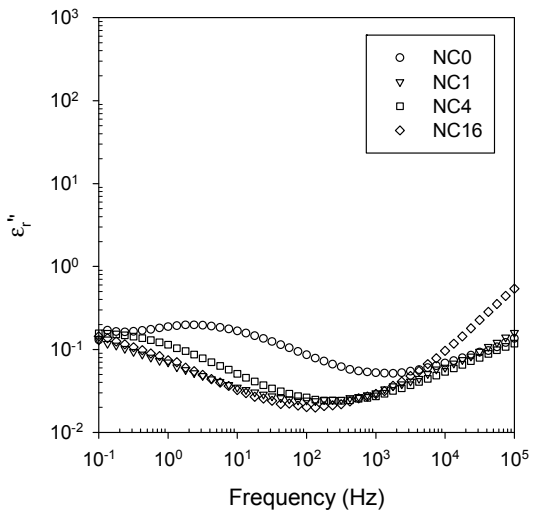

(b)

Figure 7. Dielectric data obtained at $60^{\circ} \mathrm{C}$ comparing the response of nanocomposites $\mathrm{NC} 0, \mathrm{NC} 1, \mathrm{NC} 4$ and NC16: (a) real part of the relative permittivity; and (b) imaginary part of the relative permittivity. 


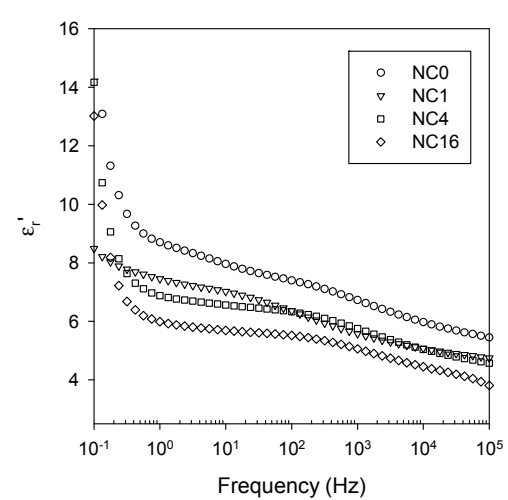

(a)

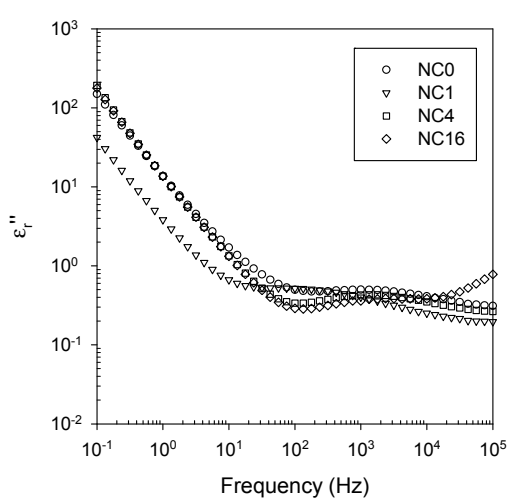

(b)

Figure 8. Dielectric data obtained at $100{ }^{\circ} \mathrm{C}$ comparing the response of nanocomposites $\mathrm{NC} 0, \mathrm{NC} 1, \mathrm{NC} 4$ and NC16: (a) real part of the relative permittivity; and (b) imaginary part of the relative permittivity.

Figure 8 shows dielectric data acquired at $100{ }^{\circ} \mathrm{C}$ from the same samples previously shown in Figure 7. The spectra recorded at $100^{\circ} \mathrm{C}$ are, however, significantly different from those collected at $60^{\circ} \mathrm{C}$, being dominated by conductivity and polarization effects, particularly at frequencies below $10^{2} \mathrm{~Hz}$. Nevertheless, the magnitude of the real part of the relative permittivity again falls progressively with increasing surface functionalization, such that $\varepsilon_{\mathrm{r}}{ }^{\prime}$ is again less in NC16 than in the unfilled EPX.

To permit further analysis, all data supporting this study are openly available from the University of Southampton repository at http://dx.doi.org/10.5258/SOTON/385542.

\section{Discussion}

A key paradigm that underpins the nanodielectric concept is that macroscopic properties are strongly affected by the presence of interphase regions, since: (a) the interphase constitutes a significant volume fraction of the system as a result of the high specific surface area of nanoparticles; and (b) that this fraction of the system is characterized by properties that are different from the bulk-perturbed molecular dynamics is commonly proposed [27-29]. The dielectric results presented above provide evidence of clear differences between the unfilled epoxy resin and those materials that contain nanosilica, which we ascribe to interfacial effects, in line with published work. Notably, the nanofilled systems all exhibit an $\alpha^{\prime}$-relaxation, which is strongly affected by the GLYMO treatment. While the DSC data demonstrate that the addition of nanosilica affects the glass transition and that the nature of this is dependent upon the nanofiller surface chemistry, the invariance of the width of the glass transition implies that the addition of nanoparticles does not, however, result in the development of a distinct interphase that differs significantly from the unperturbed matrix in terms of main-chain dynamics. In the case of controlled pore glasses, where interfacial interactions and confinement effects have been studied in detail, complex forms of behavior have been reported, which include two glass transitions, one below and one above the $T_{\mathrm{g}}$ measured for the equivalent bulk system [31] and a retardation and broadening of the glass transition [45]. In nanofilled polymers, Tsagaropoulos and Eisenberg [46] and Arrighi [47], for example, have both reported the existence of twin glass transitions, one corresponding to that of the unperturbed polymer and one related to polymer chains where interactions with the nanofiller result in reduced mobility. To rationalize the dielectric and DSC data, we suggest that the addition of the nanosilica affects the epoxy matrix in two ways, which can broadly be thought of in terms of the local behavior of small dipolar species and gross main-chain dynamics. For example, the data shown in Figure 7a equate to a progressive reduction in the polarizability of the system in going from NC0 to NC16 at a temperature below the DSC $T_{\mathrm{g}}$, where variations in the $\alpha^{\prime}$ relaxation are also apparent. We ascribe both of these effects to polar species at nanoparticle interfaces. Conversely, the glass transition, as revealed by DSC, implies that the whole of the matrix is being affected somewhat by the addition of the nanoparticles; this global effect does not, however, markedly 
influence the polarizability of the system (i.e., $\left.\varepsilon_{\mathrm{r}}{ }^{\prime}\right)$ under conditions (temperature/frequency) where main chain mobility is negligible.

In many electrical applications, dielectric breakdown strength is an important technological parameter and, therefore, the effect of nanoparticles on this has attracted considerable attention. Andritsch et al. [48], for example, considered the effect of particle size on the breakdown strength of an epoxy resin containing hexagonal boron nitride and reported a monotonic increase in strength as the filler size was reduced at the constant loading level of $10 \mathrm{wt} \%$. However, the effect of nano-structuring on breakdown is not always beneficial. In a recent study, the effect of surface chemistry on the AC breakdown strength of nanocomposites based upon nanosilica and a polyethylene blend has been described [49], in which this parameter was found to be independent of nanofiller loading level up to the point where nanofiller agglomeration became significant (5-10 wt \% in the case of unfunctionalized nanosilica; $>10 \%$ in the case of propyl-functionalized nanosilica), whereupon, inferior performance resulted. A similar dependence of breakdown strength on nanofiller loading level was also reported by Nguyen et al. [18] for epoxy/silica systems although, in this case, agglomeration of the nanofiller did not appear to be a significant factor. In the chemically treated and dried systems considered here, $E_{\mathrm{b}}$ increases for samples $\mathrm{NC} 1$ to $\mathrm{NC} 8$, before decreasing somewhat for more highly functionalized samples. Although changing the surface chemistry of the nanosilica does appear to have some effect on the dispersion state of the nanofiller, the SEM data indicate that this is relatively minor. That is, the pronounced improvement in breakdown strength that is evident in all functionalized systems is not related to improved dispersion. Indeed, in all the systems considered here, the nanoparticles are far from ideally dispersed and much more agglomerated than in the work of Nguyen et al. [18] where, despite the lack of agglomerated nanosilica, no significant increase in breakdown strength was seen.

The addition of epoxide functionality to a nanoparticle surface, as imposed here, may affect macroscopic properties in many ways. Covalent bonds will be formed with the curing resin, which will change the nature of the nanoparticle/matrix interface-mechanical integrity will be increased, for example [50]. In addition, electrically, the local density of states will change, thereby affecting charge transport through the system $[41,51]$. The process of functionalization additionally results in the replacement of hydroxyl surface groups with organic moieties, which can reduce adsorption of water molecules at nanoparticle surfaces [20]; adsorbed water has detrimental consequences. However, the silane will react with both the nanosilica surface and itself, such that residual silanol groups and epoxide functionality may be retained within the surface layer. It would appear that if this is too extensive, then the breakdown response becomes degraded.

In summary, the nature of the interactions that occur between nanoparticles and a matrix polymer are subtle and can manifest themselves in forms of behavior that can appear complex or even anomalous. In the study reported here, the consequence is an improvement in breakdown strength approaching $50 \%$ when the nanosilica was suitably functionalized. Since this cannot be related to nanoparticle dispersion effects and the DSC data provide no evidence of distinct interphase structures, we suggest that the origin of this improved performance is related to changes in interface characteristics and, in the absence of evidence for any major changes in the local structure, we suggest that variations in local trapping states/charge transport dynamics constitute a more likely explanation for the pronounced increase in breakdown strength reported.

\section{Conclusions}

A range of nanosilicas has been produced in which the surface chemistry has been systematically varied. The efficacy of the chosen organosilane chemistry has been demonstrated both by combustion analysis and FTIR spectroscopy. SEM examination of fracture surfaces indicates that the reaction of the nanosilica with increasing amounts of (3-glycidyloxypropyl)trimethoxysilane results in some improvement in nanoparticle dispersion, presumable, as a result of the presence of the introduced epoxy functionality. Nevertheless, in all cases, significant agglomerates remain and the systems described are, from a structural perspective, considerably less ideal than those that have been reported 
elsewhere [18]. However, despite this, significantly increased breakdown strength values have nevertheless been observed; this cannot be related to nanoparticle dispersion effects. In the absence of any direct evidence for distinct interphase regions between the nanosilica and the matrix polymer, which have been reported to result in multiple/broadened glass transitions, we suggest that the property enhancements we see stem from changes in the local chemistry, which result in changes in the local density of charge trapping sites and affect charge transport dynamics through the system. In particular, the substitution of hydroxyl surface character with organic moieties will markedly affect adsorption of water molecules onto nanoparticle surfaces, which manifests itself in the so-called dielectric $\alpha^{\prime}$ relaxation. However, the use of excess silane results in residual silanol groups (i.e., polar groups) being incorporated into the organic-rich surface layer, which has negative consequences for macroscopic electrical properties, even if it leads to marginally improved nanoparticle dispersion.

Acknowledgments: Celia Yeung acknowledges the receipt of an Engineering and Physical Sciences Research Council Ph.D. studentship. No funds were received to cover the costs of publishing in open access.

Author Contributions: Alun S. Vaughan conceived the experiments; Celia Yeung designed and performed the experiments; and Alun S. Vaughan and Celia Yeung analyzed the data and wrote the paper.

Conflicts of Interest: The authors declare no conflict of interest.

\section{Abbreviations}

The following abbreviations are used in this manuscript:

$\begin{array}{ll}\text { GLYMO } & \text { (3-glycidyloxypropyl)trimethoxysilane } \\ \text { FTIR } & \text { Fourier transform infrared } \\ \text { SEM } & \text { scanning electron microscope } \\ \text { DSC } & \text { differential scanning calorimeter }\end{array}$

\section{References}

1. Greco, A.; Corcione, C.E.; Maffezzoli, A. Effect of multi-scale diffusion on the permeability behaviour of intercalated nanocomposites. J. Membr. Sci. 2016, 505, 92-99. [CrossRef]

2. Corcione, C.E.; Maffezzoli, A. Transport properties of graphite/epoxy composites: Thermal, permeability and dielectric characterization. Polym. Test. 2013, 32, 880-888. [CrossRef]

3. Lewis, T.J. Nanometric dielectrics. IEEE Trans. Dielectr. Electr. Insul. 1994, 5, 812-825. [CrossRef]

4. Henk, P.O.; Korsten, T.W.; Kvarts, T. Increasing the electrical discharge endurance of acid anhydride cured DGEBA epoxy resin by dispersion of nanoparticle silica. High Perform Polym. 1999, 11, 281-296. [CrossRef]

5. Kozako, M.; Fuse, N.; Ohki, Y.; Okamoto, T.; Tanaka, T. Surface degradation of polyamide nanocomposites caused by partial discharges using IEC(b) electrodes. IEEE Trans. Dielectr. Electr. Insul. 2004, 5, 833-839. [CrossRef]

6. Fuse, N.; Kozako, M.; Tanaka, T.; Murase, S.; Ohki, Y. Possible mechanisms and superior partial discharge resistance of polyamide nanocomposites. In Proceedings of the Annual Report Conference on Electrical Insulation and Dielectric Phenomena, Boulder, CO, USA, 17-20 October 2004; IEEE: Piscataway, NJ, USA, 2004; pp. 322-325.

7. Andritch, T. Epoxy Based Nanocomposite for High Voltage DC Applications. Ph.D. Thesis, Delft University of Technology, Delft, The Netherlands, 2010.

8. Wang, Z.; Iizuka, T.; Kozako, M.; Ohki, Y.; Tanaka, T. Development of epoxy/BN composites with high thermal conductivity and sufficient dielectric breakdown strength part I-Sample preparations and thermal conductivity. IEEE Trans. Dielectr. Electr. Insul. 2001, 18, 1963-1972. [CrossRef]

9. Kochetov, R. Thermal and Electrical Properties of Nanocomposites, Including Nanomaterial Processing. Ph.D. Thesis, Delft University of Technology, Delft, The Netherlands, 2012.

10. Vassileva, E.; Friedrich, K. Epoxy/alumina nanoparticle composites. I. Dynamic mechanical behaviour. J. Appl. Polym. Sci. 2003, 89, 3774-3785. [CrossRef] 
11. Guo, Y.; Wang, M.; Zhang, H.; Liu, G.; Zhang, L.; Qu, X. The surface modification of nanosilica, preparation of nanosilica/acrylic core-shell composite latex, and its application in toughening PVC matrix. J. Appl. Polym. Sci. 2008, 107, 2671-2680. [CrossRef]

12. Chen, S.; You, B.; Zhou, S.; Wu, L. Preparation and characterisation of scratch and mar resistant waterborne epoxy/silica nanocomposite clearcoat. J. Appl. Polym. Sci. 2009, 112, 3634-3639. [CrossRef]

13. Ash, B.; Schadler, L.; Siegel, R. Glass transition behaviour of alumina/polymethylmethacrylate nanocomposites. Mater. Lett. 2002, 55, 83-87. [CrossRef]

14. Gelest Inc. Silane Coupling Agents. 2006. Available online: http://www.gelest.com/goods/pdf/ couplingagents.pdf (accessed on 30 December 2015).

15. Chen, H.; Zou, S.; Gu, G.; Wu, L. Modification and dispersion of nanosilica. J. Dispers. Sci. Technol. 2005, 25, 837-848. [CrossRef]

16. Rahimi, A.; Gharazi, S.; Ershad-Langroudi, A.; Ghasemi, D. Synthesis and characterization of hydrophilic nanocomposite coating on glass substrate. J. Appl. Polym. Sci. 2006, 102, 5322-5329. [CrossRef]

17. Witucki, G.L. A silane primer: Chemistry and applications of alkoxy silanes. J. Coat. Technol. 1993, 65, 57-60.

18. Nguyen, V.T.; Vaughan, A.S.; Lewin, P.L.; Krivda, A. The effect of resin stoichiometry and nanoparticle addition on epoxy/silica nanodielectrics. IEEE Trans. Dielectr. Electr. Insul. 2015, 22, 895-905. [CrossRef]

19. Lange, F.F.; Radford, K.C. Fracture energy of an epoxy composite system. J. Mater. Sci. 1971, 6, 1197-1203. [CrossRef]

20. Lau, K.Y.; Vaughan, A.S.; Chen, G.; Hosier, I.L.; Holt, A.F. On the dielectric response of silica-based polyethylene nanocomposites. J. Phys. D Appl. Phys. 2013, 46,1-9. [CrossRef]

21. Singha, S.; Thomas, M.J. Dielectric properties of epoxy nanocomposites. IEEE Trans. Dielectr. Electr. Insul. 2008, 15, 12-23. [CrossRef]

22. Vaughan, A.S.; Swingler, S.G.; Zhang, Y. Polyethylene nanodielectrics: The influence of nanoclays on structure formation and dielectric breakdown. IEEJ Trans. 2006, 126, 1057-1063. [CrossRef]

23. Fabiani, D.; Montanari, G.C.; Testa, L.; Schifani, R.; Guastavino, F.; Bellucci, F.; Deorsola, F. Effect of water adsorption on the dielectric properties of polymer nanocomposites. In Proceedings of the Conference Record of the 2008 IEEE International Symposium on Electrical Insulating Materials, Vancouver, BC, Canada, 9-12 June 2008; IEEE: Piscataway, NJ, USA, 2008; pp. 510-513.

24. Hui, L.; Nelson, J.K.; Schadler, L.S. The influence of moisture on the electrical performance of XLPE/silica nanocomposites. In Proceedings of the 10th IEEE International Conference on Solid Dielectrics, Potsdam, Germany, 4-9 July 2010; IEEE: Piscataway, NJ, USA, 2010.

25. Zou, C.; Fothergill, J.C.; Rowe, S.W. A "water shell” model for the dielectric properties of hydrated silica-filled epoxy nano-composites. In Proceedings of the 9th IEEE International Conference on Solid Dielectrics, Winchester, UK, 8-13 July 2007; IEEE: Piscataway, NJ, USA, 2007; pp. 389-392.

26. Lewis, T.J. Interfaces are the dominant feature of dielectrics at the nanometric level. IEEE Trans. Dielectr. Electr. Insul. 2004, 11, 739-753. [CrossRef]

27. Tanaka, T.; Kozako, M.; Fuse, N.; Ohki, Y. Proposal of a multi-core model for polymer nanocomposite dielectrics. IEEE Trans. Dielectr. Electr. Insul. 2005, 12, 669-681. [CrossRef]

28. Arantes, T.M.; Leão, K.V.; Tavares, M.I.B.; Ferreira, A.G.; Longo, E.; Camargo, E.R. NMR study of styrene-butadiene rubber (SBR) and $\mathrm{TiO}_{2}$ nanocomposites. Polym. Test. 2009, 28, 490-494. [CrossRef]

29. Miwa, Y.; Drews, A.R.; Schlick, S. Detection of the direct effect of clay on polymer dynamics: The case of spin-labeled poly(methyl acrylate)/clay nanocomposites studied by ESR, XRD, and DSC. Macromolecules 2006, 39, 3304-3311. [CrossRef]

30. Couderc, H.; Frechette, M.F.; Savoie, S.; Reading, M.; Vaughan, A.S. Dielectric and thermal properties of boron nitride and silica epoxy composites. In Proceedings of the Conference Record of the 2012 IEEE International Symposium on Electrical Insulating Materials, San Juan, Puerto Rico, 10-13 June 2012; IEEE: Piscataway, NJ, USA, 2012; pp. 64-68.

31. Corcione, C.E.; Maffezzoli, A. Glass transition in thermosetting clay-nanocomposite polyurethanes. Thermochim. Acta 2009, 485, 43-48. [CrossRef]

32. Shang, X.Y.; Zhu, Z.K.; Yin, J.; Ma, X.D. Compatibility of soluble polyimide/silica hybrids induced by a coupling agent. Chem. Mater. 2002, 14, 1-77. [CrossRef]

33. Kang, S.; Hong, S.; Choe, C. Compatibility of soluble polyimide/silica hybrids induced by a coupling agent. Polymer 2001, 42, 879-887. [CrossRef] 
34. Park, J.Y.; McKenna, G.B. Size and confinement effects on the glass transition behaviour of polystyrene/o-terphenyl polymer solutions. Phys. Rev. B 1999, 61, 6667-6676. [CrossRef]

35. Mauro, M.; Acocella, M.R.; Corcione, C.E.; Maffezzoli, A.; Guerra, G. Catalytic activity of graphite-based nanofillers on cure reaction of epoxy resins. Polymer 2014, 55, 5612-5615. [CrossRef]

36. Preghenella, M.; Pegoretti, A.; Miglairesi, C. Thermo-mechanical characterisation of fumed silica-epoxy nanocomposites. Polymer 2005, 46, 12065-12072. [CrossRef]

37. Kosmidou, T.V.; Vatalis, A.S.; Delides, C.G.; Logakis, E.; Pissis, P.; Papanicolaou, G.C. Structural, mechanical and electrical characterization of epoxy-amine/carbon black nanocomposites. Express Polym. Lett. 2012, 2, 364-372. [CrossRef]

38. Rana, D.; Sauvant, V.; Halary, J.L. Molecular analysis of yielding in pure and antiplasticized epoxy-amine thermosets. J. Mater. Sci. 2002, 37, 5267-5274. [CrossRef]

39. Hammerton, I. Recent Developments in Epoxy Resins (Rapra Review Reports); Smithers Rapra Technology: Shrewsbury, UK, 1997.

40. Schönhals, A.; Kremer, F. Analysis of dielectric spectra. In Broadband Dielectric Spectroscopy; Kremer, F., Schönhals, A., Eds.; Springer-Verlag: Berlin, Germany; Heidelberg, Germany, 2003; pp. 59-98.

41. Nelson, J.K. Dielectric Polymer Nanocomposites; Springer US: New York, NY, USA, 2010.

42. Kasprazak, W.; Nadolny, Z.; Walczak, K.; Siodla, K.; Sikorski, W.; Kozwiak, K.; Pasciak, D.; Moron, L. The influence of barium titanate as a filler in impregnating epoxy resin on chosen electrical parameters of obtained material. Mater. Sci. 2009, 27, 1219-1227.

43. Wang, Q.; Chen, G. Effect of nanofillers on the dielectric properties of epoxy nanocomposites. IEEE Trans. Dielectr. Electr. Insul. 2014, 21, 1809-1816. [CrossRef]

44. Singha, S.; Thomas, M.J. Permittivity and tan delta characteristics of epoxy nanocomposites in the frequency range of $1 \mathrm{MHz}-1 \mathrm{GHz}$. IEEE Trans. Dielectr. Electr. Insul. 2008, 15, 2-11. [CrossRef]

45. Schüller, J.; Melnichenko, Y.B.; Yu, B.; Richert, R.; Ficher, E.W. Dielectric studies of the glass transition in porous media. Phys. Rev. Lett. 1994, 73, 2224-2227. [CrossRef] [PubMed]

46. Tsagaropoulos, G.; Eisenberg, A. Dynamic mechanical study of the factors affecting the two glass transition behaviour of filled polymers: Similarities and differences with random ionomers. Macromolecules 1995, 28, 6067-6077. [CrossRef]

47. Arrighi, V.; McEwen, I.J.; Qian, H.; Serrano Prieto, M.B. The glass transition and interfacial layer in styrene-butadiene rubber containing silica nanofiller. Polymer 2003, 44, 6259-6266. [CrossRef]

48. Andritsch, T.; Kochetov, R.; Gebrekiros, Y.T.; Morshuis, P.H.F.; Smit, J.J. Short term DC breakdown strength in epoxy based BN nano- and microcomposites. In Proceedings of the 10th IEEE International Conference on Solid Dielectrics, Potsdam, Germany, 4-9 July 2010; IEEE: Piscataway, NJ, USA, 2010.

49. Lau, K.Y.; Vaughan, A.S.; Chen, G.; Hosier, I.L. Polyethylene nanodielectrics: The effect of nanosilica and its surface treatment on electrical breakdown strength. In Proceedings of the Annual Report Conference on Electrical Insulation and Dielectric Phenomena, Montreal, QC, Canada, 14-17 October 2012; IEEE: Piscataway, NJ, USA, 2012; pp. 21-24.

50. Choi, Y.Y.; Lee, S.H.; Ryu, S.H. Effect of silane functionalization of montmorillonite on epoxy/ montmorillonite nanocomposite. Polym. Bull. 2009, 63, 47-55. [CrossRef]

51. Geng, Y.; Liu, M.Y.; Li, J.; Shi, X.M.; Kim, J.K. Effects of surface treatment on mechanical and electrical properties of CNT/epoxy nanocomposites. Compos. A 2008, 39, 1876-1863. [CrossRef]

(C) 2016 by the authors; licensee MDPI, Basel, Switzerland. This article is an open access article distributed under the terms and conditions of the Creative Commons by Attribution (CC-BY) license (http://creativecommons.org/licenses/by/4.0/). 